\title{
EXPERIENCIAS DIDÁCTICAS CON RELATOS GRECOLATINOS Y SU INCORPORACIÓN EN LA ESI (EDUCACIÓN SEXUAL INTEGRAL)
}

\section{Didactical experiencies with Graeco-Latin narratives and their incorporation in the Integral Sex Education}

\author{
Paloma Cortez ${ }^{*}$ \\ Universidad de Buenos Aires \\ paloma.cortez.r@gmail.com
}

\section{Palabras clave}

Educación Sexual Integral; literatura grecolatina; género;

didáctica

\section{Keywords}

Integral Sex Education;

Graeco-latin literatura; gender;

didactic

\section{Resumen}

El presente trabajo establece un diálogo entre las propuestas formales para la implementación de la Educación Sexual Integral en las aulas (a partir de la Ley Nacional $\mathrm{N}^{\circ} 26150$ sancionada en 2006) y una serie de autorregistros de experiencias docentes en el nivel secundario, en la Ciudad Autónoma de Buenos Aires. En ellas se trabajó con la historia de amor de Penélope y Odiseo, las figuras de Circe y las sirenas y el mito de Procne y Filomena. Nuestra hipótesis es que estos relatos de la literatura clásica grecolatina, al ser revisitados con una perspectiva de género, no solo enriquecen la lectura de producciones posteriores, sino que también facilitan el tratamiento de tópicos sensibles relacionados con las desigualdades existentes entre mujeres y varones de una misma sociedad.

\begin{abstract}
This paper establishes a dialogue between the theoretical and formal proposals for the implementation/application of Integral Sex Education in the classroom (National Law No. 26150, 2006) and a series of records of teaching experiences at high school level in the city of Buenos Aires. During those experiences, we worked with Penelope and Odysseus' love story, the characters of Circe and the Sirens and Procne and Philomelas' myth. Our hypothesis is that those narratives from Graeco-latin classic literature, when revisited from a gender perspective, do not only enrich the reading of following works, but also make easier the treatment of sensible topics related to existent forms of inequality between women and men from the same society.
\end{abstract}




\section{Experiencias didácticas con relatos grecolatinos y su incorporación en la ESI (Educación Sexual Integral)}

E1 Diseño Curricular de la Nueva Escuela Secundaria (NES) sugiere y propone la lectura de ciertas obras grecolatinas para primer y segundo año, pero no ofrece ninguna indicación sobre ellas para los siguientes. Entre las propuestas para estos niveles podemos hallar la Odisea de Homero, alguna tragedia de Sófocles, la Eneida de Virgilio y las Metamorfosis de Ovidio. Sin embargo, no son de carácter obligatorio ya que no está determinado con qué textos, autores o períodos debemos trabajar lxs docentes en el aula. ${ }^{1}$ De esta manera, las decisiones acerca de las obras quedan en manos del cuerpo docente, las autoridades o, en algunos casos, del diálogo entre la escuela y su comunidad. La concepción de los roles de género ${ }^{2}$ en las distintas sociedades, y las representaciones ${ }^{3}$ literarias que se han hecho de ellos, forman parte de una tradición que se reproduce desde hace siglos y llega al presente. La literatura, en tanto “tecnología del género" (De Lauretis, 1987), oficia como productora y reproductora de estas identidades estereotípicas y su abordaje desde una perspectiva generizada arroja luz sobre múltiples conflictos sociales. ${ }^{4}$ Si bien puede mostrar la realidad de una comunidad, también puede direccionar o perpetuar su organización. En cualquier caso, incide sobre las decisiones de lxs receptorxs. Como afirma Laura Arnés:

Ficciones son aquellas construcciones discursivas, ideológicas e imaginarias fundantes de los lazos sociales que se concentran, se combinan y superponen (...) aquellas que se transforman en dominantes son las que poseen no solo un gran poder de seducción sino, también, un gran potencial de disciplinamiento. $(2015$, p. 126)

Los roles y las concepciones atribuidas al género están estereotipados por los discursos sociales. Asimismo, son verificables continuidades, como también rupturas, respecto de la cultura grecolatina, cuya influencia se percibe actualmente también en otros ámbitos - como el Derecho y la estructuración familiar-. Por estos motivos y, de acuerdo con la Ley Nacional $N^{\circ} 26150$ que hace fundamental a la tarea docente para la toma de conciencia y consecuente erradicación de las desigualdades entre varones y mujeres, ${ }^{5}$ se torna importante reflexionar sobre la pertinencia del estudio reflexivo de las producciones literarias de la Antigüedad en la escuela secundaria.

1. Elegimos la forma inclusiva con " $\mathrm{x}$ " para esta palabra y otras que designen al grupo de estudiantes de acuerdo con las propuestas de la Guía para una comunicación con perspectiva de género del Ministerio de las Mujeres, Género y Diversidad (2019, p. 17).

2. La definición de género a la cual adherimos combina las reflexiones de Butler (1988) y De Lauretis (1996) y podríamos formularla de la siguiente manera: el género es una categoría que representa su construcción y a su vez se construye con cada representación, de manera circular y está íntimamente relacionado con las representaciones artísticas y culturales.

3. Entendemos "representación" en el sentido en el que lo usa Chartier, es decir, como la producción de sentido que realizan los individuos a través del lenguaje y la literatura. Por medio de esta, se configura la concepción que tienen de ellos mismos y su relación con el mundo. Cfr. Chartier (2005), El mundo como representación.

4. Para el concepto de estereotipo seguimos a R. Cook y S. Crusack (2010).

5. Artículo 3, e) de la Ley Nacional N² 26150 "Procurar igualdad de trato y oportunidades para varones y mujeres". 
La preocupación por la enseñanza de los clásicos en la escuela secundaria y las dificultades a las que se enfrenta el cuerpo docente para llevar a cabo esta práctica han sido objeto de diferentes estudios (Garcés, 2015; Hunt, 2018). Para acompañar estas investigaciones, proponemos que los relatos en torno a las figuras de Penélope, Circe y las sirenas de Odisea ${ }^{6}$ y el mito de Procne y Filomena de Metamorfosis $^{7}$ al ser revisitados con perspectiva de género enriquecen la lectura de producciones posteriores y facilitan el tratamiento de tópicos sensibles relacionados con las desigualdades entre mujeres y varones de una misma sociedad.

Las experiencias que desarrollaremos a continuación son observaciones a partir de autorregistros de clases dictadas en segundo y quinto años de una escuela privada y laica de CABA. Los programas de estos niveles no incluyen explícitamente la lectura de obras clásicas pero sus temáticas resultaron pertinentes en tres oportunidades: en primer lugar, como intertexto para la interpretación de la novela La mujer habitada de Gioconda Belli; ${ }^{8}$ en segundo lugar, en el marco de una actividad interdisciplinaria con el Departamento de Ciencias Sociales que tenía por objeto dar a conocer los orígenes del sistema democrático; y por último, en ocasión de una jornada ESI cuyo tema a tratar era el desarrollo de las competencias comunicativas. Para llevar a cabo las actividades se utilizó una metodología semejante a la propuesta por Nieto (2019) que integra un aula de estudio, en la que leímos, comentamos e interpretamos de manera conjunta los textos seleccionados; una de producción en donde se les pidió a lxs estudiantes una monografía y un guion teatral y una de transferencia en la que las representaciones sociales exhibidas por la literatura nos permitieron reflexionar sobre nuestras relaciones y nuestra vida cotidiana. A continuación, expondremos algunas observaciones sobre la experiencia realizada en estas tres oportunidades.

\section{Penélope, la esposa por antonomasia}

La lectura de La mujer habitada de Gioconda Belli (1988), realizada en quinto año (ciclo lectivo 2018) nos llevó a reflexionar sobre la figura de Penélope y su rol en la conformación del deber ser femenino. La protagonista de la novela, Lavinia, se queja en reiteradas oportunidades de verse reducida a una Penélope y decide para sí misma otro destino: buscará formar parte del grupo guerrillero al que pertenece su compañero en lugar de quedarse a esperarlo, con la angustia de no saber si regresará a salvo y con la incomodidad de no hacer nada para cambiar la realidad con la que también ella se siente disconforme. Podemos ver en Lavinia la voluntad de romper con el estereotipo en el cual se reconoce. Hernández (2012) ha realizado un estudio centrado en el análisis de la recomposición y reescritura de temas clásicos, a cargo de autores del siglo XX. Allí afirma que ciertos modelos femeninos (Penélope, Fedra, Medea y Electra) a pesar de haberse establecido como canon, no permanecen inmutables a lo largo de los años, sino que se han ido modificando conforme cambiaron los componentes sociales y los roles de género (Hernández, 2012, p. 194).

6. Para esta actividad utilizamos la traducción de J. M. Pabón editada por Gredos (2000).

7. Realicé una adaptación propia a partir del texto latino y la traducción de E. Roillé editada por Losada (2012).

8. Utilizamos la edición de Emecé (1996). 
Una de las consignas para el análisis fue establecer una comparación entre los personajes de Lavinia y de Sara, su amiga desde la infancia, y reflexionar sobre sus diferencias. Lxs estudiantes identificaron que las dos eran de clase alta y habían sido educadas para ser amas de casa, pero Lavinia "se emancipa de su familia y de los estereotipados trabajos 'de mujer' estudiando arquitectura y mudándose sola, cuestión que escandaliza a su familia” mientras que Sara se instala con comodidad en el rol que le fue socialmente asignado. ${ }^{9}$ Como trabajo final, lxs alumnxs tenían que elaborar una monografía y, podían utilizar esta obra, entre las otras del programa. Malena realizó una monografía titulada "Militantes políticos y Penélope" en la que desarrolla cómo Felipe, el héroe de la novela, a pesar de sus ideas revolucionarias, buscaba relacionarse con una mujer tradicional, modelada a imagen de Penélope, tal como Lavinia percibía:

Una de las particularidades de Lavinia es que se da cuenta de sus semejanzas con Penélope y le desagrada porque 'No quería hacer de Felipe el centro de su vida; devenir de Penélope hilando las telas de la noche' (p.114) y le generaba pesar, 'ella, moderna Penélope a su pesar' (p. 114). ${ }^{10}$

En el análisis realizado por esta alumna, se menciona la ruptura que realiza Lavinia respecto del modelo de mujer exigido, implícitamente, por su novio. ${ }^{11}$ También afirma que ella falta a su rol de Penélope por alistarse al Movimiento y por mantener esta acción en secreto de su pareja. A continuación, extrae una conclusión del desenlace de los eventos mencionados que muestra con claridad cómo esta lectura le permitió repensar las relaciones interpersonales y los roles de género, en sus palabras: "Ser ellos los únicos en la relación que mantienen secretos, porque están con mujeres que son, supuestamente, incapaces de ocultarles algo les ayuda a reafirmar su masculinidad y dominio sobre ellas".

\section{Monstruos femeninos}

La primera actividad que realicé en segundo año (ciclo lectivo 2019) con literatura clásica fue a pedido de los profesores del área de Ciencias Sociales, quienes querían representar una asamblea ateniense para dar a conocer cómo era la democracia practicada en Atenas y pensaron basar algunos argumentos del debate en pasajes literarios. Con este objetivo, leímos en clase dos escenas de Odisea: la de Circe (X, 133-574) y la de las sirenas (XII, 1-200) para pensar a partir de ellas qué representación tienen las voces femeninas en la obra. En la primera se observa a una diosa que canta bonito y teje en su palacio, reuniendo así dos características relacionadas con lo femenino. Ella invita a los guerreros a un banquete y los envenena al ofrecerles "un perverso licor que olvidar les hiciera la patria" (Od.X. 236). Como consecuencia se convierten en cerdos. Sin embargo, uno de ellos había permanecido fuera y pude avisarle a Odiseo de lo acontecido. El héroe de la epopeya se salva de las artes de Circe gracias

9. Transcripción de una conclusión emitida por un estudiante durante la clase.

10. Citado de la monografía "Militantes políticos y Penélope".

11. Sería interesante, para otra oportunidad en la que podamos trabajar con el intertexto de Eneida, atender al simbolismo que despierta el nombre de la protagonista en la novela de Belli. 
a la asistencia de Hermes y la convence de restituir las formas humanas de sus compañeros hechizados. El segundo pasaje seleccionado muestra unas muy atractivas figuras femeninas, las sirenas, que con su dulce canto convencen a los hombres de quedarse con ellas evitando que regresen a su patria con sus familias. Lxs profesorxs involucradxs en el proyecto sabíamos cómo funcionaba la democracia ateniense y buscamos en el relato homérico los argumentos para justificar por qué una mujer no podía participar de ella; la tarea para el alumnado fue pensar esta exclusión por sí mismxs. Nuestra intención era que reflexionaran sobre las posibilidades que tenían las mujeres en una sociedad cuyas bases culturales están instaladas en las grandes épicas, la Ilíada y la Odisea. En este sentido, coincidimos con Sardi (2019, p. 89) en que "todos los textos literarios pueden ser leídos desde una perspectiva de género -aun aquellos textos que históricamente han conformado el canon escolar-" siempre que se proponga la reflexión en torno al género y se habiliten las interpretaciones de lxs estudiantes.

La elección de los personajes, la realizamos en conjunto con la profesora de lengua de primer año, quien también participó del proyecto. Nos pareció prudente dar a conocer las figuras de Circe y las sirenas que funcionan a modo de hipertexto en obras posteriores que las incluyen como personajes o, por lo menos, las mencionan. El resultado de la lectura de los pasajes homéricos en que aparecían estos monstruos femeninos fue la toma de conciencia por parte del alumnado del peligro que significaban. Circe seducía a los guerreros y los engañaba con un alimento hechizado y las sirenas eran capaces de dominar las mentes de los héroes. En este segundo caso, los marineros habían sido advertidos con antelación sobre ellas y no corrieron el riesgo de ser persuadidos, pero en la curiosidad de Odiseo, se puede ver con claridad el peligro: él era el único que podía escucharlas, pero debía permanecer atado y sus soldados tenían la estricta orden de no liberarlo para que su cuerpo no pudiera reaccionar a los encantos de estas 'mujeres'. Es decir, que ni siquiera el gran héroe de la epopeya podía resistirse a su dañino poder de seducción, como se extrae de los versos 192-194: "Tal decían [las sirenas] exhalando dulcísima voz y en mi pecho yo anhelaba escucharlas. Frunciendo mis cejas mandaba a mis hombres soltar mi armadura”. A partir del análisis de las escenas, concluyeron que la intervención femenina, su apariencia, sus palabras y su -engañosa- hospitalidad ponen en riesgo la misión de los héroes masculinos y ese fue el argumento utilizado en la representación de la asamblea para prohibir la participación de las mujeres en las votaciones.

\section{Procne y Filomela}

El último autorregistro para comentar será el de una jornada ESI realizada en segundo año. El requisito en esta oportunidad para el ciclo básico fue trabajar con "El desarrollo de competencias comunicativas relacionadas con la expresión de necesidades y/o solicitud de ayuda ante situaciones de vulnerabilidad de derechos" (Jornada Nacional "Educar en Igualdad”, p. 17). Pensé, entonces, trabajar con un texto clásico, ya que la experiencia con los pasajes de Odisea había sido muy fructífera y el curso mostraba interés en la mitología grecolatina. Elegí el mito de Procne y Filomela que es uno de los más explícitos de las Metamorfosis de Ovidio, debido a sus episodios violentos. Tereo se había casado con Procne luego de un acuerdo con Pandión, padre de esta, y la había llevado a vivir a Tesalia. Ella, un tiempo después, pide ver a su hermana y el esposo viaja para buscarla. Al verla, una pasión 
lo invade y decide poseerla aun contra su voluntad. La joven Filomena luego de haber sido violada siente que está manchada para siempre y que ha traicionado a su hermana, por haber atraído -aunque involuntariamente- a su marido. Este, al verse amenazado por la denuncia de Filomena, mutila su lengua y la encierra en una torre. Sin embargo, ella hallará a través de un tejido la manera de narrar la historia a Procne quien vendrá a rescatarla y planearán juntas una venganza que pondrá fin a la vida de Itis, el hijo de Procne y Tereo. Seguramente la sumatoria de actos de violencia haya dejado este relato fuera del canon de mitos griegos y latinos para público juvenil. Sin embargo, la experiencia frente a las aulas me ha mostrado que, en general, las historias fuertes, violentas, que generan reacciones a medida que se leen, tienen buena recepción en la escuela secundaria.

Durante la jornada leímos el mito, ligeramente adaptado, en voz alta. Luego, trabajamos con tres ejes que habían sido preparados como disparadores para generar una instancia de reflexión: 1) la cosificación de las hermanas, 2) la capacidad de expresarse, y 3) la sensación de responsabilidad de la víctima.

Con respecto al primer eje notamos que tanto para Pandión, padre de las jóvenes, como para Tereo, marido de Procne y violador de su cuñada, ellas eran 'objeto' y sus voluntades no eran tenidas en cuenta. Esta conclusión se desprende de considerar, por un lado, que Pandión pautó el matrimonio de Procne guiado por la conveniencia de una alianza sociopolítica (vv. 424-428), y consideraba a su hija menor como un consuelo para su vejez (v. 501). Por el otro, que Filomela es representada en la narrativa como un objeto de deseo irrefrenable para Tereo (v. 513).

En cuanto al segundo eje, la capacidad de expresarse, que era el propuesto por el Ministerio de Educación, reflexionamos sobre la astucia de Filomela, quien, al verse privada de su posibilidad de hablar y encerrada en una torre, se las ingenia para comunicarle a su hermana lo que había ocurrido mediante un tejido (vv. 553-586). La hermana mayor, al enterarse de los hechos queda muda del impacto y solo se dedica a planear una venganza que atenta también contra ella misma (vv. 583-586). En ambos casos, a falta de palabras, se recurre a la acción. Finalmente, Tereo hace un uso del lenguaje absolutamente negativo. Persuade con engaños a Pandión y a Filomela y les transmite confianza a pesar de que ya tiene planeado el crimen (vv. 455-471). Luego intenta persuadir a Filomela para procurarse un momento de intimidad (vv. 519-526) y no lo logra. Su persuasión en este caso fracasa y lo que no consigue con las palabras, lo alcanza mediante la violencia.

La discusión acerca de la responsabilidad de la víctima nos llevó a repensar en la subjetividad de Filomela quien dice merecer el castigo de un enemigo y que mejor habría sido morir y convertirse en una sombra inmaculada (vv. 540-541) antes de ser manchada por el crimen de su cuñado. Si bien el encuentro con Tereo fue en contra de su voluntad, ella tiene vergüenza de mirar a los ojos a su hermana. Se siente manchada y se siente rival.

Las respuestas de lxs estudiantxs ante la propuesta de debate fueron las siguientes. La brutalidad del crimen de las hermanas fue comprendida por Tomás que manifestó que seguramente no tenían otra manera de hacer justicia en el mundo antiguo y menos aún en rivalidad con un rey. Es interesante que haya despertado en este alumno las nociones de injusticia y desigualdad, es decir, la certeza de que 
una mujer no podría reclamar justicia inculpando a un rey, simplemente porque el rey es más poderoso que ella. A este comentario se agregaron quienes dijeron que a ella nadie le creería y que a lo largo del relato se hace hincapié en la belleza de la joven. Esto lxs hizo recordar comentarios muy actuales en los casos de violación en los que se responsabiliza a la víctima por considerar que su apariencia es atractiva y provocadora. La incapacidad de obtener justicia reconocida por Tomás en primera instancia y aceptada por sus pares, se relaciona íntimamente con la incapacidad de expresión. Procne, una vez que conoce la historia, podría contarla y acusar a Tereo por haberla ultrajado a ella y a su hermana, pero, como bien dijeron, en términos fácticos no puede. En su caso no es la mutilación de la lengua lo que le impide expresarse, sino la sociedad. Otrxs alumnxs agregaron, nuevamente en línea con la realidad contemporánea, que quizás ellas no podían contar lo que había ocurrido y pedir justicia por vergüenza y por miedo y que Filomela podía sentirse responsable por no haberse defendido lo suficiente. También, que por eso ella siente que engañó a la hermana. Retomamos en este punto la idea de que el énfasis que el relato hace sobre la belleza de la joven podría generar en Filomela o en cualquier víctima de violencia de género, culpa por ser bella. Esto fue relacionado por una de las estudiantes con la realidad contemporánea en algunas religiones actuales en las que las mujeres deben ocultar su pelo, su rostro, o la contextura de su cuerpo porque todos esos elementos de la mujer son considerados atractivos y la mujer que los muestra es culpable de una falta a la religión.

Queda a la vista que la lectura de este mito nos permitió debatir y reflexionar sobre una amplia variedad de ejes. Además de los mencionados, dio lugar a que lxs alumnxs planteen temas emergentes como la intención de poder diferenciar el amor de la obsesión y la preocupación acerca de los piropos callejeros. Sobre esto, Bianca comentó que se siente violentada o intimidada cuando le dicen piropos en la calle, ya que notó que cuando camina junto a su padre nadie le dice nada. Esto la llevó a interpretar que quieren que tenga miedo, por eso lo hacen cuando está sola y no cuando está junto a un varón mayor que podría defenderla, si fuera necesario. La conversación acerca de los piropos es un claro ejemplo de puesta en cuestión de una conducta que no necesariamente es condenada por la sociedad ni interpretada como abuso, sin embargo, es percibida como tal.

\section{Consideraciones finales}

En las tres experiencias desarrolladas se observa que lxs estudiantes pueden reconocer en ciertos textos de la literatura grecolatina roles de género que les resultan de fácil vinculación con experiencias de desigualdad en la vida comunitaria actual y les permiten reflexionar sobre ellas. Constatar esto, teniendo en consideración el rol de la literatura en la conformación de las representaciones del género, nos permite abrir el diálogo en torno a problemáticas actuales y su herencia de la tradición cultural. Según el recorrido trazado, el trabajo con la literatura clásica se mostró pertinente para el enriquecimiento de interpretaciones de obras literarias contemporáneas y de fenómenos cívicosociales. Por otro lado, puesto que el análisis de pasajes de Odisea y del mito de Procne y Filomela nos permitió reflexionar acerca de la desigualdad y la violencia de género, vemos con claridad que realizando lecturas generizadas de la literatura clásica se pueden trabajar los contenidos de Educación Sexual Integral. Por último, quisiéramos concluir esta comunicación señalando que nuestros proyectos 
y nuestro trabajo día a día en el aula deben ser pensados a la luz de la ESI, dando lugar a los temas de discusión emergentes y permitiendo que lxs estudiantxs continúen las líneas interpretativas que las lecturas les sugieren.

\section{Referencias bibliográficas}

Arnés, L. (2015). Ficciones del género: Modos de leer, modos de enseñar, modos de escribir. Exlibris, 4, 215-219.

Belli, G. (1996). La mujer habitada. Buenos Aires, Emecé.

Butler, J. (2007). Sujetos de sexo/ género/ deseo. En Butler, J., El género en disputa. El feminismo y la subversión de la identidad (pp. 45-99). Barcelona, Paidós. (Original de 1990.)

Chartier, R. (2005). El mundo como representación. Barcelona, Gedisa. (Original de 1995.)

Ley 26150 de 2006. Programa Nacional de Educación Sexual Integral. Boletín Nacional, Buenos Aires, 24 de octubre de 2006. https://bit.ly/3w90IPb.

Cook, R. y Cousack, S. (2010). Gender Stereotyping: Transnational Legal Perspectives. Philadelphia, University of Pennsylvania Press.

De Lauretis, T. (1987). Technologies of Gender. Essays on Theory, Film, and Fiction. Bloomington, Indiana University Press.

Estrella Garcés, S. O. y Andrade Zapata, J. S. (2015). La vigencia de la literatura clásica griega en la educación contemporánea: De Homero a Woody Allen. PUCE. https://bit.ly/2TlybYv.

Hernández, C. F. (2012). Ejemplos de relectura de la tradición clásica en clave de literatura de género. Methodos, 1, 193-199.

Homero (1993). Odisea. (J. Pabón, trad.). Madrid, Gredos.

Hunt, S. (2018). Getting Classics into Secondary Schools: Three Case Studies. The Journal of Classics Teaching, 38, 64-70.

Ministerio de Educación y Deportes de la Nación (2016). Jornada Nacional Educar en igualdad: prevención y erradicación de la violencia de género, Ley $\mathrm{N}^{\circ} 27234$, Orientaciones para las instituciones educativas. https://bit.ly/3vb95J3.

Ministerio de las Mujeres, Género y Diversidad (2019). (Re)nombrar, Guía para una comunicación con perspectiva de género. https://bit.ly/3v6Rphx.

Nieto, F. (2019). ¿Cómo enseñar literatura en la escuela secundaria? Notas para una metodología en construcción. Educación, Lenguaje y Sociedad, XVII, 17, 1-37.

Ovidio (2010). Metamorfosis. (E. Rollié, trad.). Buenos Aires, Losada. 
Sardi, V. (2019). Lengua y literatura. En Colectivo Mariposa Mirabal (ed.), Educación Sexual Integral. Epistemología, pedagogía y politica en los debates curriculares (pp. 79-96). Buenos Aires, Facultad de Filosofía y Letras, UBA.

*Paloma Cortez es graduada de la Licenciatura y el Profesorado en Letras con orientación en Letras Clásicas por la Universidad de Buenos Aires (UBA). Actualmente se encuentra realizando un doctorado en la misma institución sobre la novela bizantina Drosila y Caricles (s. XII). Es becaria de un proyecto PICT-2017-0387 “La narrativa en el Bizancio temprano (ss. IV-IX)” y es integrante-estudiante de un proyecto FILO:CyT "La enseñanza de la literatura clásica en los niveles medio y superior: ESI, canon y género literario". En este último se enmarca la investigación presentada en el artículo.

RECIBIDO: 31/03/2021

ACEPTAdo: $10 / 06 / 2021$ 